\title{
Mechanisms of Saccadic Suppression in Primate Cortical Area V4
}

\author{
ํ)Theodoros P. Zanos, ${ }^{1,2}$-Patrick J. Mineault, ${ }^{3}$ Daniel Guitton, ${ }^{1}$ and Christopher C. Pack ${ }^{1}$ \\ ${ }^{1}$ Montreal Neurological Institute, McGill University, Montreal, Quebec H3A2B4, Canada, ${ }^{2}$ Center for Bioelectronic Medicine, Feinstein Institute for Medical \\ Research, Manhasset, New York 11030, and 3Neurobiology Department, University of California, Los Angeles, Los Angeles, California 90095-1763
}

Psychophysical studies have shown that subjects are often unaware of visual stimuli presented around the time of an eye movement. This saccadic suppression is thought to be a mechanism for maintaining perceptual stability. The brain might accomplish saccadic suppression by reducing the gain of visual responses to specific stimuli or by simply suppressing firing uniformly for all stimuli. Moreover, the suppression might be identical across the visual field or concentrated at specific points. To evaluate these possibilities, we recorded from individual neurons in cortical area V4 of nonhuman primates trained to execute saccadic eye movements. We found that both modes of suppression were evident in the visual responses of these neurons and that the two modes showed different spatial and temporal profiles: while gain changes started earlier and were more widely distributed across visual space, nonspecific suppression was found more often in the peripheral visual field, after the completion of the saccade. Peripheral suppression was also associated with increased noise correlations and stronger local field potential oscillations in the $\alpha$ frequency band. This pattern of results suggests that saccadic suppression shares some of the circuitry responsible for allocating voluntary attention.

Key words: alpha; LFP; primate; saccades; suppression; V4

\section{Significance Statement}

We explore our surroundings by looking at things, but each eye movement that we make causes an abrupt shift of the visual input. Why doesn't the world look like a film recorded on a shaky camera? The answer in part is a brain mechanism called saccadic suppression, which reduces the responses of visual neurons around the time of each eye movement. Here we reveal several new properties of the underlying mechanisms. First, the suppression operates differently in the central and peripheral visual fields. Second, it appears to be controlled by oscillations in the local field potentials at frequencies traditionally associated with attention. These results suggest that saccadic suppression shares the brain circuits responsible for actively ignoring irrelevant stimuli.

\section{Introduction}

To observe our visual surroundings, we constantly move our eyes. The main purpose of these frequent shifts of our gaze is to position the center of our retina, which contains the highest density of photoreceptors, on behaviorally relevant areas of our visual field. These rapid displacements of our retinal image would

\footnotetext{
Received March 23, 2016; revised July 13, 2016; accepted July 16, 2016.

Author contributions: T.P.Z., D.G., and C.C.P. designed research; T.P.Z. performed research; T.P.Z. and P.J.M. analyzed data; T.P.Z., P.J.M., and C.C.P. wrote the paper.

This work was supported by Canadian Institutes of Health Research Grants MOP-115178 (C.C.P.) and MOP-9222 (D.G.) and Natural Sciences and Engineering Research Council Grant 341534-12 (C.C.P.). We thank Julie Coursol and Cathy Hunt for outstanding animal care and Drs. Fernando Churaund and Julio Martinez-Trujillo for help with surgeries. Dr. Jachin Monteon collected preliminary data, and Drs. Matthew Krause and Stavros Zanos provided helpful comments on data analysis.

The authors declare no competing financial interests.

Correspondence should be addressed to either Theodoros P. Zanos or Christopher C. Pack, Montreal Neurological Institute, McGill University, 3801 University Avenue, \#896, Montreal, QC H3A2B4, Canada. E-mail: tzanos@northwell.edu or christopher.pack@mcgill.ca.

DOI:10.1523/JNEUROSCI.1015-16.2016

Copyright $\odot 2016$ the authors $\quad 0270-6474 / 16 / 369227-13 \$ 15.00 / 0$
}

normally produce a perception of sudden jumps of our visual field, a potentially unpleasant experience akin to the viewing of a video taken with a very shaky camera. The fact that our visual perception remains stable is therefore a result of neuronal mechanisms that compensate for these displacements (Wurtz, 2008). One of the best known mechanisms is a saccadic suppression of visual processing that occurs around the time of each eye movement (Matin et al., 1972).

Whereas saccadic suppression has been well documented both psychophysically (Burr et al., 1982, 1994; Burr and Morrone, 1996; Ross et al., 1996, 2001; Diamond et al., 2000; Castet et al., 2002; Knöll et al., 2011; Dorr and Bex, 2013; Guez et al., 2013; Gu et al., 2014) and neurophysiologically (Fischer et al., 1996; Ramcharan et al., 2001; Reppas et al., 2002; Thiele et al., 2002; Ibbotson et al., 2008; Bremmer et al., 2009), there is some disagreement about the underlying mechanisms. One plausible candidate is a saccade-triggered reduction in the gain of visual responses (Burr et al., 1994, 1999; Ross et al., 1996; Diamond et al., 2000; Knöll et al., 2011; Watson and Krekelberg, 2011; Gu et al., 2014). This would entail a multiplicative scaling of 
visual responses, and evidence for such a mechanism has recently been found in macaque primary visual cortex (V1; McFarland et al., 2015). Alternatively, saccadic suppression might involve additive influences on visual responses that are independent of any specific stimulus. Evidence for this mechanism comes from a variety of psychophysical and neurophysiological studies (Krekelberg et al., 2003; Binda et al., 2009; McFarland et al., 2015).

There has also been some question about the retinotopic organization of saccadic suppression. Early studies reported stronger suppression of stimuli near the foveal part of the visual field (Osaka, 1987), as well as faster recovery from suppression in the fovea than in the periphery (Mitrani et al., 1970). However, more recent work has shown that suppression, expressed as a multiplicative gain, is constant across retinal eccentricities (Knöll et al., 2011). This issue has not, to our knowledge, been examined in single neurons.

We have examined these issues in visual cortex area V4, where neurons are known to be strongly modulated by both visual stimuli and saccades (Fischer and Boch, 1981). Area V4 also contains a retinotopic map of visual space (Gattass et al., 1988; Mineault et al., 2013), and previous work in human (Kleiser et al., 2004) and nonhuman (Han et al., 2009) primates shows evidence for saccadic suppression in this area. To investigate the nature of the suppression and its retinotopic organization, we trained monkeys to make visually guided saccades while we mapped single-neuron receptive fields (RFs) using random white-noise visual stimuli (Zanos et al., 2015). A model-based approach (Mineault et al., 2013) allowed us to separate and track the multiplicative and additive parts of the responses of V4 neurons in space and time.

Our results demonstrate neural correlates of saccadic suppression in a significant number of V4 neurons. The nature of this suppression changes dynamically around the time of saccades, both in its retinotopic organization and its mechanistic aspect, transitioning from a multiplicative suppression that is uniform across all eccentricities to an additive influence that is exclusive to neurons with peripheral RFs. We also found that the retinotopic component of suppression was accompanied by a strong increase in $\alpha$ band oscillations $(7-13 \mathrm{~Hz}$ ) of the local field potentials (LFPs), suggesting that some portion of saccadic suppression is related to attentional mechanisms that have been described in other contexts (Jensen et al., 2012).

\section{Materials and Methods}

\section{Electrophysiological recordings}

The recording methods have been described previously (Zanos et al., 2011a; Mineault et al., 2013). Briefly, two macaque monkeys (Macaca mulatta, one male and one female) underwent a sterile surgical procedure for implantation of a headpost and a chronic $10 \times 10$ microelectrode array in area V4 (Utah array; Blackrock Microsystems). Area V4 was identified based on stereotactic coordinates, anatomical landmarks (Ghose and Ts'o, 1997), and the physiological properties of the neurons (Gattass et al., 1988). After recovery, each monkey was seated in a primate chair (Crist Instruments) and trained to maintain fixation and to make visually guided saccades toward stimuli presented on a screen, for liquid reward. All aspects of the experiments were approved by the Animal Care Committee of the Montreal Neurological Institute and were conducted in compliance with regulations established by the Canadian Council of Animal Care.

Signal acquisition and preprocessing. We recorded wideband signals using a standard data acquisition system (Multichannel Acquisition Processor System; Plexon), custom modified to allow sampling at $10 \mathrm{kHz}$ (bandpass filtered using hardware filters between 0.07 and $2500 \mathrm{~Hz}$ ) over the 96 channels of each Utah array. Subsequent spike sorting and LFP analysis were performed through off-line digital filtering. We monitored the power spectrum of these wideband signals on a daily basis to mini- mize line noise and other artifacts. The remaining $60 \mathrm{~Hz}$ noise (and possible harmonics) was removed off-line with a power spectrum correction method introduced previously (Zanos et al., 2011b). Recordings were referenced against a ground located on the skull $2-3 \mathrm{~cm}$ away from the array.

Off-line analysis was aimed at detecting single-neuron and LFP activity on each channel. To detect single-unit waveforms, we first bandpass filtered the raw signal between 500 and $4000 \mathrm{~Hz}$; spike detection and sorting were then performed using established methods (Quiroga et al., 2004). To avoid double-counting of single neurons during consecutive days of recordings, we began each recording session by displaying the same sequence of 100 natural images, repeated 10 times, while the monkey maintained fixation. The response of each neuron to this sequence, along with the shape of the action potential and the interspike interval histograms, was collected. We then computed pairwise correlations of these measures for all neurons found on different electrodes or days of recordings. Neurons that showed high correlations were deemed to be repeats and were discarded from further analysis.

We estimated the LFP signals by removing action potential waveforms from the wideband signal using a Bayesian method (Zanos et al., 2011b); the despiked signal was then bandpass filtered $(0.2$ to $150 \mathrm{~Hz})$ and downsampled to $500 \mathrm{~Hz}$ to produce the LFP signals. All off-line digital filtering was implemented with Matlab software (Mathworks), using a fourthorder, two-pass Butterworth filter (digital filter with zero phase delay).

\section{Behavioral task and visual stimuli}

The visual stimuli were back-projected on a semitransparent screen by a CRT video projector, refreshed at $75 \mathrm{~Hz}$. The screen covered an area of $80 \times 50^{\circ}$ of visual angle at a viewing distance of $78 \mathrm{~cm}$. The monkeys were required to maintain fixation within $1.5^{\circ}$ of the fixation point or saccade target for $500 \mathrm{~ms}$ to obtain a liquid reward on each trial. Eye position was monitored at $1000 \mathrm{~Hz}$ using an infrared eye tracker (Eyelink; SR Research).

LFP retinotopy. LFP and single-unit receptive fields were estimated using our previously published method (Mineault et al., 2013). Briefly, we found that multiunit and LFP receptive fields were generally matched in preferred spatial position. However, because the LFP is the more robust signal, being present on nearly every electrode on every day of recording, we used the LFP to estimate retinotopy in the current study. The retinotopic component of each LFP receptive field was well captured by a Gaussian in log-polar coordinates (i.e., log-eccentricity and polar angle), whereas the gain of this envelope was modulated as a function of time lag relative to stimulus onset (Mineault et al., 2013). We fit measured LFP responses through least-squares minimization of the parameters of the Gaussian function. A receptive field was deemed significantly tuned if the fit to the Gaussian was significant at the $p<0.0001$ level according to a $\chi^{2}$ test (Wood, 2006; Mineault et al., 2013). From these fits, we estimated eccentricity values at each electrode position (Mineault et al., 2013; Zanos et al., 2015).

Saccade experiments. As described previously in detail (Churan et al., 2011, 2012), for the saccade experiments, we used a random sparse noise stimulus to stimulate visual neurons in V4, without introducing stimulus-related correlations in their activity (Fig. 1). The sparse noise stimulus consisted of $50 \%$ black $\left(<2.0 \mathrm{~cd} / \mathrm{m}^{2}\right)$ and $50 \%$ white $(30.5$ $\left.\mathrm{cd} / \mathrm{m}^{2}\right)$ squares presented at random positions on a gray background $(7.0$ $\mathrm{cd} / \mathrm{m}^{2}$; Fig. $1 A$ ). The positions of the black and white squares changed randomly at the frame rate of $75 \mathrm{~Hz}$; each square was $1^{\circ}$ across, and collectively the squares covered $2 \%$ of the screen area on each frame. We chose a stimulus with broadband frequency and orientation content because it allowed us to probe saccadic suppression without making strong assumptions about the preferences of the neurons under study. The specific parameters were chosen based on our empirical observations that they drove the neurons well. We note that the dominant spatial frequency in the stimulus was $0.5 \mathrm{c} /$, for which saccadic suppression is found psychophysically (Burr et al., 1994).

At the beginning of each trial, there was a random 600-1400 ms fixation period before the saccade target was presented and the fixation point disappeared (Fig. 1). The monkey was then required to make a visually guided saccade to the target immediately after its appearance and was 


\section{A Saccade towards RFs}

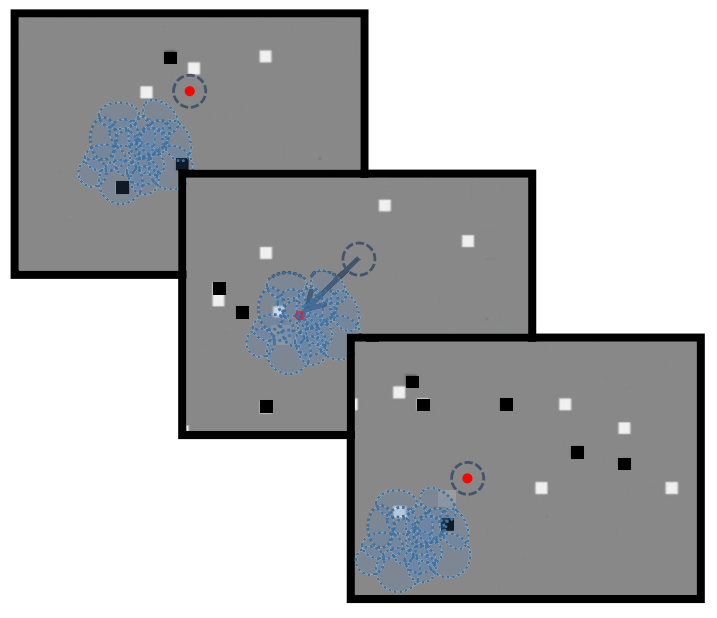

B

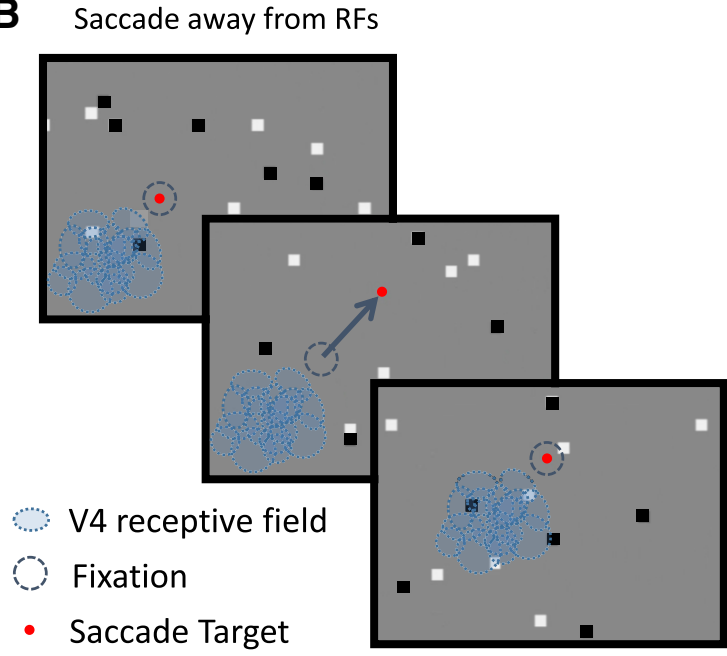

C

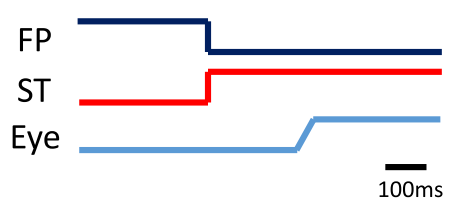

Figure 1. Schematic diagram of the saccade experiment. Monkeys made saccades (blue arrows) to visual targets (red dots) over a sparse white-noise background stimulus, composed of black and white dots against a light gray background. $A, B, V 4$ receptive fields (blue ovals) were positioned in both monkeys in the lower left part of the visual field, thus separating the saccades into two groups, saccades toward $(\boldsymbol{A})$ and away $(\boldsymbol{B})$ from the RFs. $\boldsymbol{C}$, Sketch of the temporal properties of the saccade experiment, with the lines representing the relative timing of the fixation point (FP), the saccade target (ST), and a typical eye movement (Eye). After a random duration period of fixation, the fixation point disappeared and simultaneously the saccade target appeared and remained on for the rest of the trial. The latency of the saccade from saccade target appearance was typically $150-200 \mathrm{~ms}$.

required to hold fixation on the target for $300 \mathrm{~ms}$. The orientation of the visually guided saccades in all recordings was diagonal, either toward or away from the receptive fields under study (Fig. 1), and the amplitude was $10^{\circ}$. Typically, $\sim 3000-4000$ trials were collected during each recording session.

To examine the contribution of visual signals to the perisaccadic LFPs, we performed additional experiments in which the monkeys performed $10^{\circ}$ saccades in total darkness (background luminance, $\ll 0.01 \mathrm{~cd} / \mathrm{m}^{2}$ ) without any sparse noise stimulation in the background. Finally, to test the importance of oculomotor signals, we examined an artificial saccade condition, consisting of steady fixation while the background visual stimulus shifted diagonally $10^{\circ}$ back and forth every second, imitating a shift of the background during an actual saccade. Since we were limited by the refresh frequency of the projector $(75 \mathrm{~Hz})$, the total displacement of the background was completed in three frames to correspond roughly to the duration of a regular saccade $(40 \mathrm{~ms})$.

\section{Data analysis}

Eye movements. Saccade onset was determined as the time when the eye trace left the fixation window. Saccade end was determined as the time following saccade onset when the velocity of the eye trace fell to a value below $10 \%$ s.

Suppression index. We quantified the amount of saccade-related suppression for each neuron by calculating a suppression index (SI), similar to that used in previous studies (Bremmer et al., 2009) to capture the change in perisaccadic firing rates relative to the presaccadic baseline. Our SI typically ranged from -1 to 1 , with positive values indicating saccadic suppression and negative values indicating a perisaccadic enhancement of firing rates: $\mathrm{SI}=(1-$ (perisaccadic response/presaccadic response)). We calculate the perisaccadic response as the mean perisaccadic firing rate for time windows of specific width relative to the end of the saccade, and we define the presaccadic response as the mean firing rate of the neuron during fixation (500-300 ms before saccade end). The time windows used to calculate this index were $75-0 \mathrm{~ms}$ before saccade end, $0-75 \mathrm{~ms}$, and $75-150 \mathrm{~ms}$ after saccade end, consistent with previous studies (Bremmer et al., 2009) that used similar windows to separate effects caused by active and passive suppression.

Receptive field estimation. To estimate receptive field envelopes, we assumed that neuronal responses were given by the following:

$$
y(t) \sim \sum_{x, y, \tau, k} S(x, y, t-\tau, k) w(x, y) v(\tau) u(k)+c+\epsilon(t) .
$$

Here, $y(t)$ are the measured spikes, sampled at the frame rate of the stimulus $(75 \mathrm{~Hz}) ; S$ is the stimulus in eye-centered coordinates; $w$ is the spatial kernel; $v$ is the temporal kernel; $u$ is the gain with respect to stimulus contrast $(k=1$ corresponding to black, $k=2$ corresponding to white); $c$ is the baseline firing rate; and $\varepsilon(t)$ corresponds to independent and identically distributed Gaussian noise. We excluded from this analysis periods of time in which the eye was not within $2^{\circ}$ of the target for $\pm 62.5 \mathrm{~ms}$ around the analysis time; this effectively excluded both times around fixational eye movements and around blinks.

We estimated the parameters $v$ and $u$ through maximum likelihood via alternating least-squares (Ahrens et al., 2008). We assumed that $w$ was smooth and localized and estimated it through automatic locality determination (Park and Pillow, 2012). We used a fit/validation design where, for every $10 \mathrm{~s}$ of data, the first $9 \mathrm{~s}$ were assigned to the fit dataset and the last second was assigned to the test dataset. We fit the model on the fit dataset and predicted the results on the test dataset. We excluded neurons for which the coefficient of determination for the test dataset $r_{\text {validation }}^{2}<$ 0.0004 from further analysis. We then fit a two-dimensional Gaussian via least-squares to $w(x, y)$ to establish the position and eccentricity of the receptive fields.

To ensure that receptive field positions were stable through time, we computed the spike-triggered average (STA) of each receptive field in 60 $\mathrm{ms}$ bins centered at different time points relative to each saccade. We factorized these receptive field slices using singular value decomposition and used the ratio of the square of the first singular value to the sum of the squares of all singular values as an index of separability of the slices; an 
index of 1 would indicate the receptive fields only shifted in gain through time, whereas an index of 0 would indicate that the receptive fields change structure through time. We found the distribution to be heavily skewed toward 1 and manually inspected the least separable receptive fields; these were generally noisy with no evidence of perisaccadic remapping.

Gain and offset analysis. Having estimated receptive field envelopes, we then examined the effect of saccades on the gain of neural firing and baseline firing rate. For a given saccade direction, we took neural responses in a range from -500 to $500 \mathrm{~ms}$ around the start of a saccade; we call this time $\delta$. We fit a model for the response around the time of a saccade:

$$
\begin{aligned}
y(t+\delta) \sim \sum_{x, y, \tau, k} g(\delta) S(x, y, t+\delta-\tau, & k) w(x, y) v(\tau) u(k) \\
& +(\beta(\delta)+1) c+\epsilon(t)
\end{aligned}
$$

To fit this model, we kept $w(x, y), v(\tau)$, and $u(k)$ constant from the original receptive field fit and fit the time-dependent gain $g(\delta)$ and the time-dependent offset $b(\delta)$ through maximum likelihood. By definition, $g(\delta)$ is normalized to be centered around 1 and $b(\delta)$ around 0 .

Wavelet transform of LFPs. To acquire time-frequency representations of our LFP signals and to determine any spectral modulations related to eye movements, we used the Morlet-based wavelet transform (Goupillaud et al., 1984). We filtered the LFP with complex Morlet wavelets and used the magnitude of the coefficients as an estimate of the instantaneous power of the LFP at each frequency. We normalized the magnitude of the coefficients around the time of saccade end by the average magnitude of the coefficients of the LFP signal, to obtain a normalized wavelet saccadetriggered average, which can reveal transient increases or decreases in the magnitude of oscillations at given frequencies around the occurrence of saccades.

Spike-field coherence and conditional spiking probability. To further quantify the tendency of spiking to occur in certain phases of the LFP at different frequencies, we calculated the spike-field coherence (SFC), as the power spectrum of the STA, divided pointwise by the sum of the power spectra of all LFP segments used to compute the STA (Fries et al., 2001). SFC ranges between 0 and 1; a value of 1 at a given frequency means that all spikes occur at the same phase for that frequency, whereas a value of 0 means that there is no preferred phase in that frequency.

To calculate the conditional spiking probability, for a given $\alpha$ LFP power value, we used the Kolmogorov definition of conditional probability:

$$
P\left(\text { spike } \mid \alpha \operatorname{LFP}_{\text {power }}\right)=\frac{P\left(\text { spike } \cap \alpha \mathrm{LFP}_{\text {power }}\right)}{P\left(\alpha \mathrm{LFP}_{\text {power }}\right)} .
$$

$P\left(\right.$ spike $\left.\cap \alpha \mathrm{LFP}_{\text {power }}\right)$ is the joint probability of a spike occurrence for a given $\alpha$ LFP power value, computed as the distribution of the instantaneous $\alpha$ LFP power for each spike occurrence for all V4 neurons and their corresponding electrodes. $P\left(\alpha \mathrm{LFP}_{\text {power }}\right)$ is the marginal distribution of $\alpha$ power, computed as the distribution of instantaneous $\alpha$ LFP power values for all recordings, regardless of spike occurrence.

\section{Results}

Area V4 is a part of the primate visual cortex that is known to have both visual (Desimone and Schein, 1987; Connor et al., 1996) and oculomotor (Fischer and Boch, 1981; Moore, 1999) responses. The RFs of V4 neurons and LFPs are organized retinotopically, so that the area contains a map of contralateral visual space (Gattass et al., 1988; Mineault et al., 2013). To study the dynamics of neural signals across this map, we chronically implanted $10 \times 10$ microelectrode arrays into dorsal V4 of two macaque monkeys. We examined the activity of single neurons and LFPs during experiments in which the monkeys made saccades into and out of the area of the visual field accessible to the implanted arrays, while we simultaneously presented a sparse noise visual stimulus (Fig. 1). This paradigm allowed us to observe the neural re- sponses to visual stimuli and saccades and the interaction between them.

\section{Postsaccadic modulation of V4 neuron firing rate}

We measured the perisaccadic responses of 265 visually responsive single neurons to the sparse noise visual stimulus from experiments $(n=18)$ in which at least 1000 total saccades were completed. The visual stimulus consisted of random white and black squares that changed position on each frame (Fig. 1; Zanos et al., 2015). Figure 2 shows the raster plots and the average of the perisaccadic activity of two example V4 neurons; responses were recorded while the monkey performed $10^{\circ}$ diagonal saccades both toward and away from the visual hemifield represented by the recording array. The average traces at the bottom of each panel show that the firing rate of one neuron decreased (Fig. $2 A$ ) whereas that of the other one increased (Fig. $2 B$ ) shortly after (60-140 ms) the completion of a saccade. In both cases, the saccade-related modulation of the firing rate was greater for toward saccades (blue) than for away saccades (red).

We quantified the amount of saccade-related suppression for each neuron by calculating a SI, similar to that used in previous studies (Bremmer et al., 2009; see Materials and Methods) to capture the change in perisaccadic firing rates relative to the presaccadic baseline. Our SI typically ranged from -1 to 1 , with positive values indicating saccadic suppression and negative values indicating a perisaccadic enhancement of firing rates.

We examined SI values for the population of single neurons at various times relative to the saccade, and the resulting histograms are shown in Figure 2C. For saccades away from the RFs (red), there is, on average, little modulation of firing rates during the first two time windows ( -75 to 0 and $0-75 \mathrm{~ms}$ ); this modulation does not significantly deviate from zero ( $t$ test, $p=0.18$ and $p=$ 0.68 , respectively). For the third time window $(75-150 \mathrm{~ms})$, there is a small but significant increase in suppression (mean SI, 0.065; $t$ test, $p<0.05$ ). Thus, for away saccades there is, on average, little change in the firing rate.

However, closer inspection of the distributions in Figure $2 C$ reveals that the variance of the distributions increased substantially during the latter part of the perisaccadic response (paired f-test with first and second time window distributions, both $p<0.01)$. This suggests that different groups of neurons became either more suppressed or more enhanced during this time window, as is also suggested by the examples in Figure 2, $A$ and $B$.

These effects are more pronounced for toward saccades, with the distribution of SI values evolving from a unimodal distribution in the first window to a bimodal distribution (Hartigan's dip test, $p<0.05$ ) in the third time window. This suggests the existence of two distinct groups of neurons that are either enhanced or suppressed in the immediate postsaccadic period. Note that the saccade target appeared typically 200-300 ms before the completion of the saccade (Fig. 1C). Although "reactivation" responses to visual stimuli have been observed before saccades (Moore et al., 1998), these are generally excitatory, and so they would not contribute to the suppression we report here.

\section{Properties of perisaccadic firing rate modulation}

To quantify the perisaccadic modulation of visual sensitivity, we computed neuronal receptive fields at various times relative to each saccade. In particular, we used a model-based approach (see Materials and Methods and zharv;53Mineault et al., 2013) that allowed us to track changes in both the gain 
A

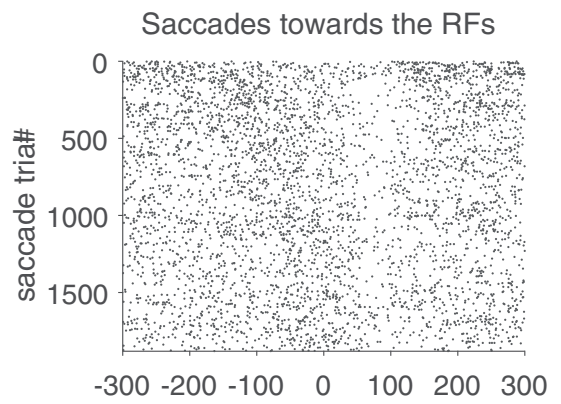

Saccades away from the RFs
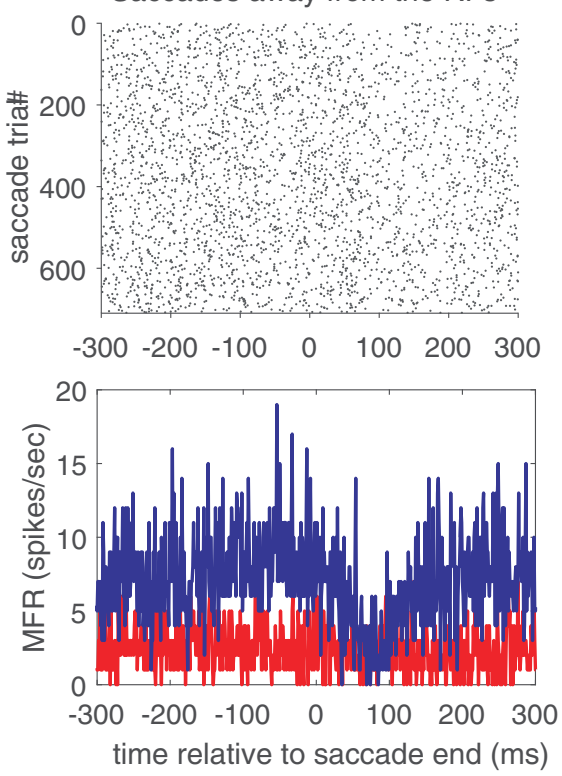

B

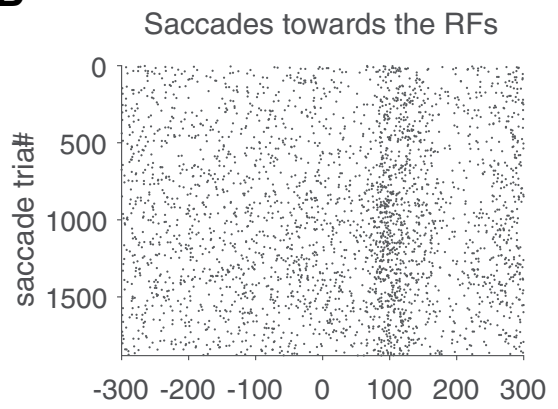

Saccades away from the RFs
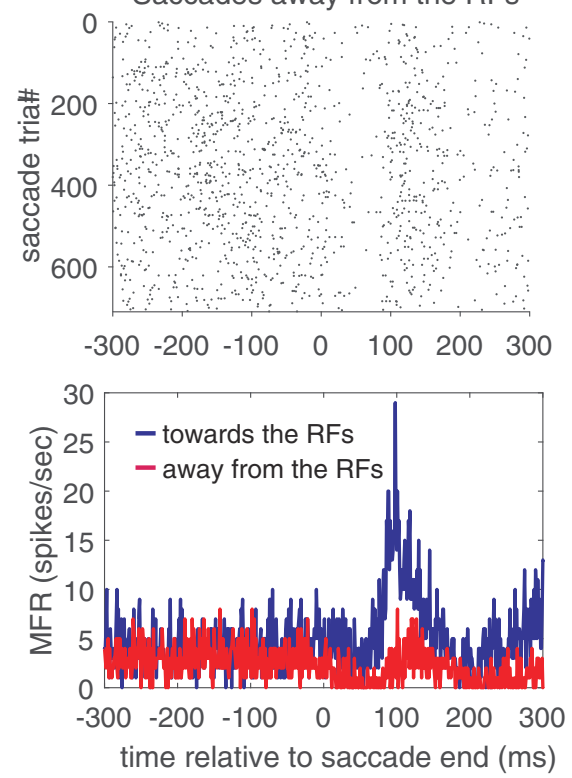

\section{C}
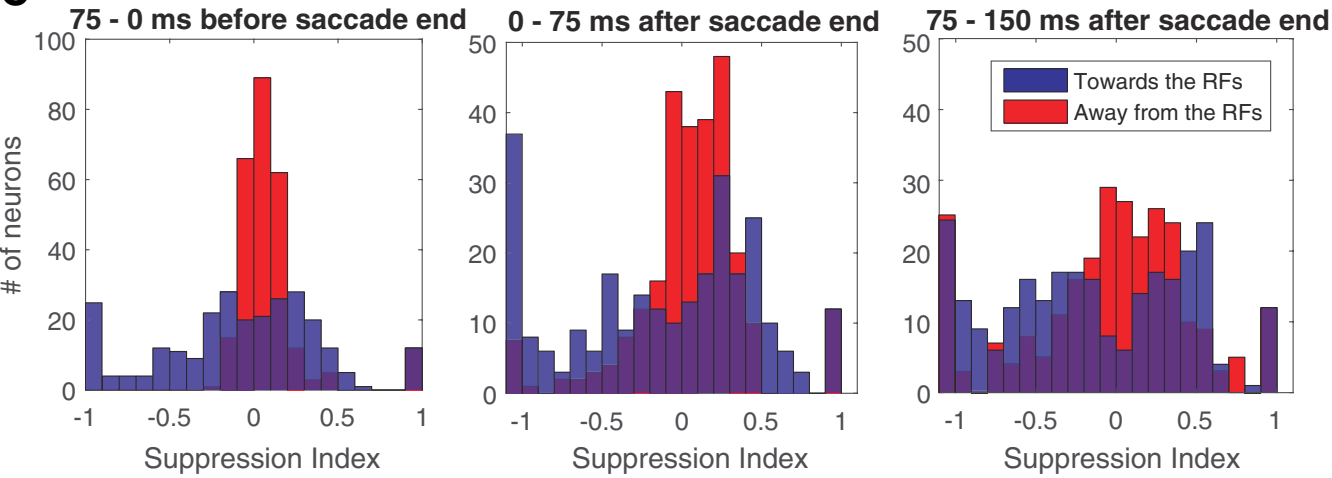

Figure 2. Perisaccadic modulation of V4 neuron firing rates. $A, B$, Raster plots and average perisaccadic activity of two example V4 neurons; responses were recorded while the monkey performed $10^{\circ}$ diagonal saccades both toward and away from the visual hemifield represented by the recording array. MFR, Mean Firing Rate. Average responses are plotted relative to the completion of toward (blue) and away (red) saccades. C, Histograms of suppression index values for the population of V4 neurons at three time windows ( -75 to 0 ms, $0-75 \mathrm{~ms}$, and $75-150 \mathrm{~ms}$ ) relative to the saccade end, for toward (blue) and away (red) saccades.

and the baseline of V4 neuron responses. The gain corresponds to a multiplicative scaling of responses to stimuli in the receptive field, whereas the baseline represents a nonspecific, additive change in firing rates. A change in either parameter could manifest as suppression, but with different consequences for stimulus coding (see Discussion).

We first verified that receptive field positions were stable in retinal coordinates around the time of each saccade. Previous work (Tolias et al., 2001; Neupane et al., 2016a,b) has shown that V4 neurons change position with each saccade, but there is some evidence that remapping mainly occurs for salient stimuli
(Churan et al., 2011; Joiner et al., 2011). Because we presented many stimuli that changed position rapidly, there was little salience attributable to any one stimulus. Consistent with these previous results, the average magnitude of receptive field shifts from the presaccadic to the postsaccadic period was not significantly different from $0^{\circ}$ (one-sample $t$ test, $p>0.05$ ).

Figure $3 A$ illustrates the spatial RF of an example V4 neuron at six different perisaccadic time intervals, with the times above each panel indicating when the responses occurred relative to the end of the saccade. Figure $3 B$ indicates the perisaccadic values of the gain (left) and baseline (right) parameters, with the times 
A
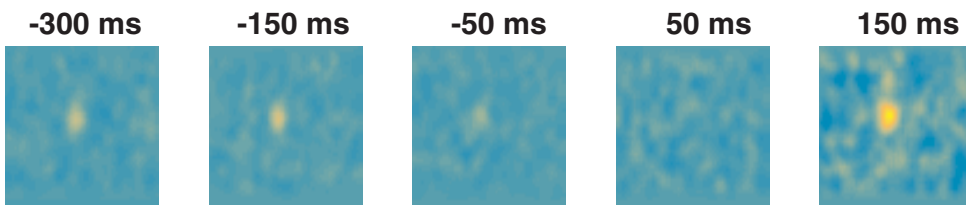

$300 \mathrm{~ms}$

B
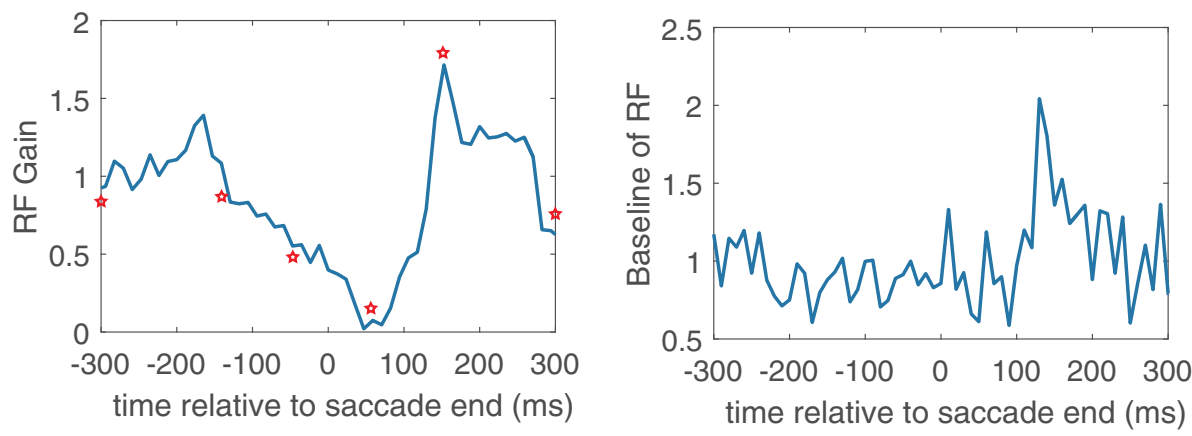

C
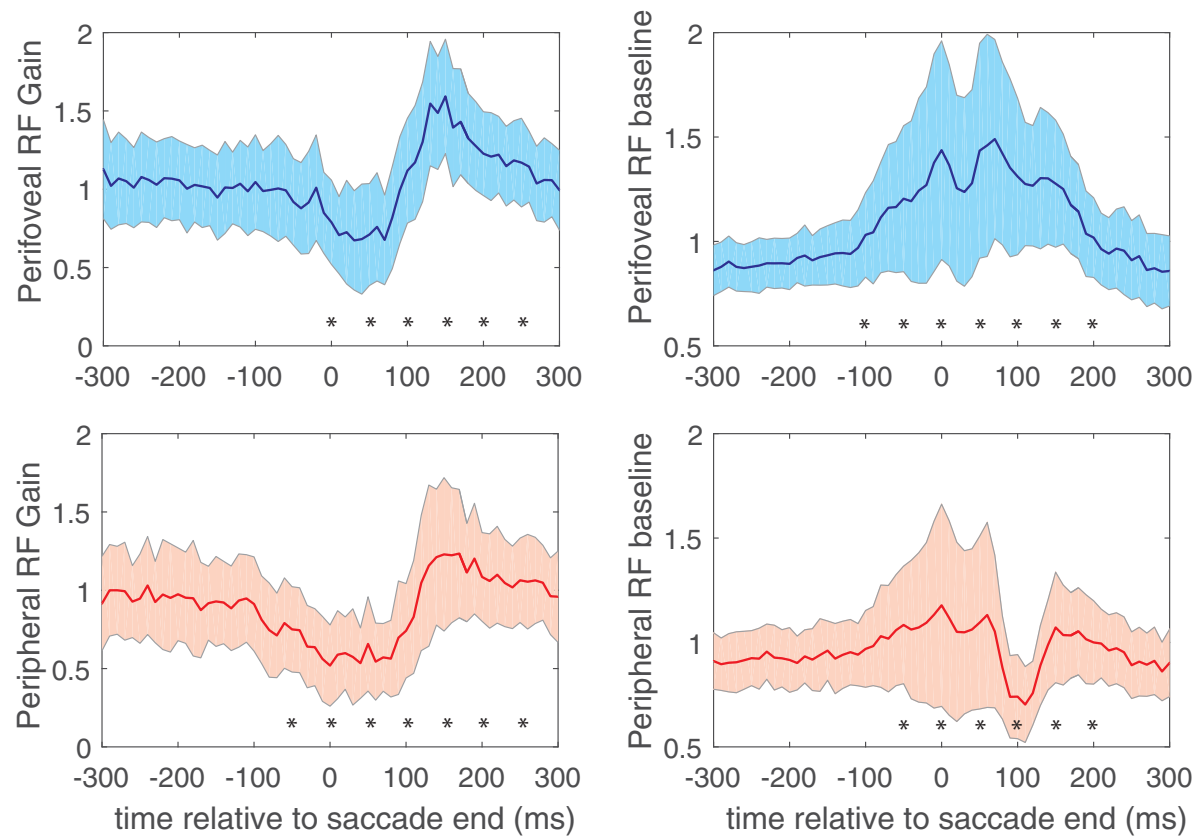

Figure 3. Perisaccadic receptive field modulation. $\boldsymbol{A}$, Spatial receptive field of an example V4 neuron at six different perisaccadic time intervals, with the times above each panel indicating when the responses occurred relative to the end of the saccade. $\boldsymbol{B}$, Perisaccadic values of the gain (left) and baseline (right) parameters for this neuron, with the red stars corresponding to the receptive field plots in A. C, Average time course of the modulation in both gain (left) and baseline (right) parameters for all perifoveal (top) and all peripheral (bottom) neurons. Asterisks indicate 100 ms bins in which the measured quantity was significantly different from its presaccadic value (two-tailed $t$ test, $p<0.05$ ).

corresponding to Figure $3 A$ denoted on the gain curve as red stars. Both the gain and baseline of this $\mathrm{V} 4$ receptive field were modulated as a function of time relative to saccade end.

To examine whether changes in the gain and baseline parameters of the RFs differ across retinal space, we sorted the V4 population into two populations based on eccentricity. Neurons were categorized as perifoveal if they had receptive field centers with eccentricities $<15^{\circ}$ and peripheral otherwise.

Figure $3 C$ shows the average time course of the modulation in both gain and baseline parameters for all perifoveal and all peripheral neurons. For both populations of neurons, the gain parameter shows a characteristic time course (Fig. 3C, left), with suppression being followed by enhancement. In contrast, the baseline parameter (Fig. 3C, right) exhibits different dynamics for the two populations. For perifoveal neurons, the RF baseline increases from $\sim 100 \mathrm{~ms}$ before to $150 \mathrm{~ms}$ after the saccade. In contrast, for peripheral neurons, the baseline is suppressed $\sim 50$ $150 \mathrm{~ms}$ after saccade end. The distributions of gain and baseline parameters differed significantly from presaccadic levels ( $t$ tests, $p<0.05)$ during the period between 0 and $200 \mathrm{~ms}$ after the saccade (Fig. 3C, asterisks).

Across the population, postsaccadic changes in the baseline parameter were inversely correlated with receptive field eccentricity $(r=-0.38, p<0.01)$. The relationship between eccentricity and peak-to-peak modulation of the gain parameter was far weaker and did not reach significance $(r=-0.14, p=0.08)$. Overall, these results suggest the presence of two saccadic suppression mechanisms that differentially affect the gain and base- 
line of V4 RFs and that are manifested retinotopically in different ways.

\section{Saccades increase $\alpha(7-13 \mathrm{~Hz})$ LFP power for peripheral V4 sites}

Previous work has shown that the excitability of individual neurons is regulated by ongoing oscillations in local network activity (Steriade et al., 1993; Fiser et al., 2004; Lakatos et al., 2005, 2009). These oscillations can be detected in the LFPs recorded simultaneously with spiking activity, and they can be used by other brain regions to establish a behavioral context that shapes sensory responses (Lakatos et al., 2005; Rajkai et al., 2008; Zanos et al., 2015). To determine whether oscillations might be implicated in saccadic suppression, we analyzed the perisaccadic LFPs across the electrode arrays.

We first examined whether there were specific frequency bands whose power was modulated perisaccadically. To this end, we calculated the continuous wavelet transform, using Morlet wavelets as the basis functions (Goupillaud et al., 1984), and averaged the power of the resulting wavelet coefficients around the time corresponding to the end of each saccade. This saccadetriggered wavelet average across all sessions is plotted in Figure $4 A$, and it shows a strong increase of power in frequencies below $15 \mathrm{~Hz}$ and especially at the $7-13 \mathrm{~Hz}$ band, commonly referred as the $\alpha$ LFP frequency band. This band has been shown to be associated with suppression of neuronal firing (Nir et al., 2007; Jensen and Mazaheri, 2010; Haegens et al., 2011).

We next sought to determine whether the fluctuations in $\alpha$ could be related to the eccentricity-dependent changes in firing rate seen in Figure 3. As shown in previous work (Mineault et al., 2013), the retinotopy of the LFP signal in V4 is well matched to that of the neuronal outputs. We therefore asked whether the distribution of firing rate changes could be related to changes in $\alpha$ fluctuations at the same sites.

Figure $4 B$ (top row) shows changes in $\alpha$ LFP power for the perifoveal electrodes (left) and peripheral electrodes (right) during toward saccades. Although there is a significant increase in $\alpha$ LFP power for both perifoveal and peripheral electrodes around the same time (paired $t$ test, $p<0.01$ for both electrode groups), it is significantly higher (two-sample $t$ test, $p<0.01$ ) for the peripheral electrodes. Overall, for toward saccades, there was a significant correlation $(r=0.42, p<0.01)$ between the peak modulation of $\alpha$ LFP power and the receptive field eccentricity. Similarly, $\alpha$ power during the $200 \mathrm{~ms}$ after each saccade was inversely related to the firing rates $(r=-0.145, p<0.02)$ and baseline activity $(r=-0.33, p<0.01)$ of single neurons, but not their multiplicative gain $(r=-0.04, p=0.49)$.

The modulation of $\alpha$ power was generally weaker for away saccades (Fig. $4 C$, bottom row), and there was no correlation with RF eccentricity ( $r=0.06$, Fig. $4 C$, right). Thus, it is clear that $\alpha$ LFP power is modulated by saccades in a manner that depends on saccade direction and receptive field position. The time course of this modulation appears to match that of the changes in RF gain and baseline (Fig. 3).

To estimate retinal and extraretinal contributions to these effects, we performed control experiments in which the monkeys either performed eye movements in the absence of any visible background (saccades in the dark) or maintained fixation while the background stimulus was swept across the visual field at saccadic velocities (artificial saccades). For saccades in the dark, the average normalized perisaccadic $\alpha$ LFP power for perifoveal and peripheral electrodes (Fig. 5A, left) follows a modulation pattern similar to that seen for saccades in the light (Fig. 4). Specifically, $\alpha$ power is modulated significantly $90 \mathrm{~ms}$ after saccade end (paired $t$ test, $p<0.01$ for both perifoveal and peripheral electrodes, both saccade directions) with peripheral electrodes being modulated more strongly than perifoveal ones (two-sample $t$ test, $p<0.01$ ) for toward saccades.

For the artificial saccades, $\alpha$ LFP power was not significantly modulated, for both perifoveal and peripheral electrodes (paired $t$ test of normalized $\alpha$ LFP power values $90 \mathrm{~ms}$ after saccade end, $p>0.05$ ) and both saccade directions (Fig. 5B). These results suggest that $\alpha$ modulation is triggered by the saccade itself and that it is sensitive to the saccade direction, highlighting a likely role for extraretinal signals in saccadic suppression.

\section{Impact of $\alpha$ LFP power on spike rates and noise correlations}

From Figure 4, it is apparent that the largest perisaccadic LFP modulation is associated with $\alpha$ power and with sites that have peripheral RFs. These sites also exhibit reduced firing rates at the same time (Fig. 3C, bottom right). Because $\alpha$ oscillations are thought to reflect inhibitory control processes (Klimesch et al., 2007), one hypothesis is that single-neuron saccadic suppression is related to an entrainment of neural firing by $\alpha$ oscillations. To test this idea, we calculated SFC between V4 neurons and $\alpha$ oscillations in $100 \mathrm{~ms}$ sliding windows around the time of each saccade.

Figure $6 \mathrm{~A}$ shows an example of the SFC calculated for a peripheral neuron with an eccentricity of $27.7^{\circ}$. For this site, there is a large postsaccadic increase in SFC at $\alpha(7-13 \mathrm{~Hz})$ frequencies around the occurrence of the saccade. The increase in $\alpha$ coherence is clearly much stronger for saccades toward the RFs (Fig. $6 A$, left) than for saccades away from the RFs (Fig. 6A, right). There is no significant $\alpha$ SFC increase for the example of a perifoveal V4 neuron with an eccentricity of $7.9^{\circ}$, in either saccade direction (Fig. 6B).

To examine whether the same effects were present across our perifoveal and peripheral neurons, we calculated population averages of the $\alpha$ SFC values around the time of each saccade, for both groups of neurons and both saccade directions (Fig. 6C). The $\alpha$ SFC was stronger for peripheral neurons during the window $50-150 \mathrm{~ms}$ after the end of saccades toward the RFs (Fig. $6 \mathrm{C}$, left, red trace), which corresponds to the interval with the strongest increase in $\alpha$ power. These values were stronger than the perifoveal values for the same saccade direction (paired $t$ test, $p<$ 0.01 ) and both perifoveal and peripheral values for the opposite saccade direction (Fig. 6C, right; two-sample $t$ test, $p<0.01$ ).

The locking of peripheral neuronal spikes at a specific time window relative to saccade end implies that the common fluctuating input arriving to these neurons, as reflected by the $\alpha$ band of the LFP, affects the exact timing of their action potentials. To examine whether this common input had an effect on the collective dynamics of the population of V4 neurons, we calculated the pairwise noise correlations between all possible pairs of neurons, among and within the perifoveal and peripheral groups, for three different time windows and for both saccade directions. The results (Table 1) show that the correlations within the peripheral neuronal group during the window of 75-150 ms after saccade end, and only for saccades toward the RFs, are significantly higher than all other windows and saccade directions (repeatedmeasures ANOVA, $p<0.01$ ) as well as significantly higher than correlations of all other neuronal groups (one-way ANOVA, $p<$ 0.01 ). This suggests that at the same time that peripheral neurons decrease their firing, their variability becomes more correlated. This pattern of results is similar to that found for unattended stimuli (Cohen and Maunsell, 2009; Mitchell et al., 2009). 
A
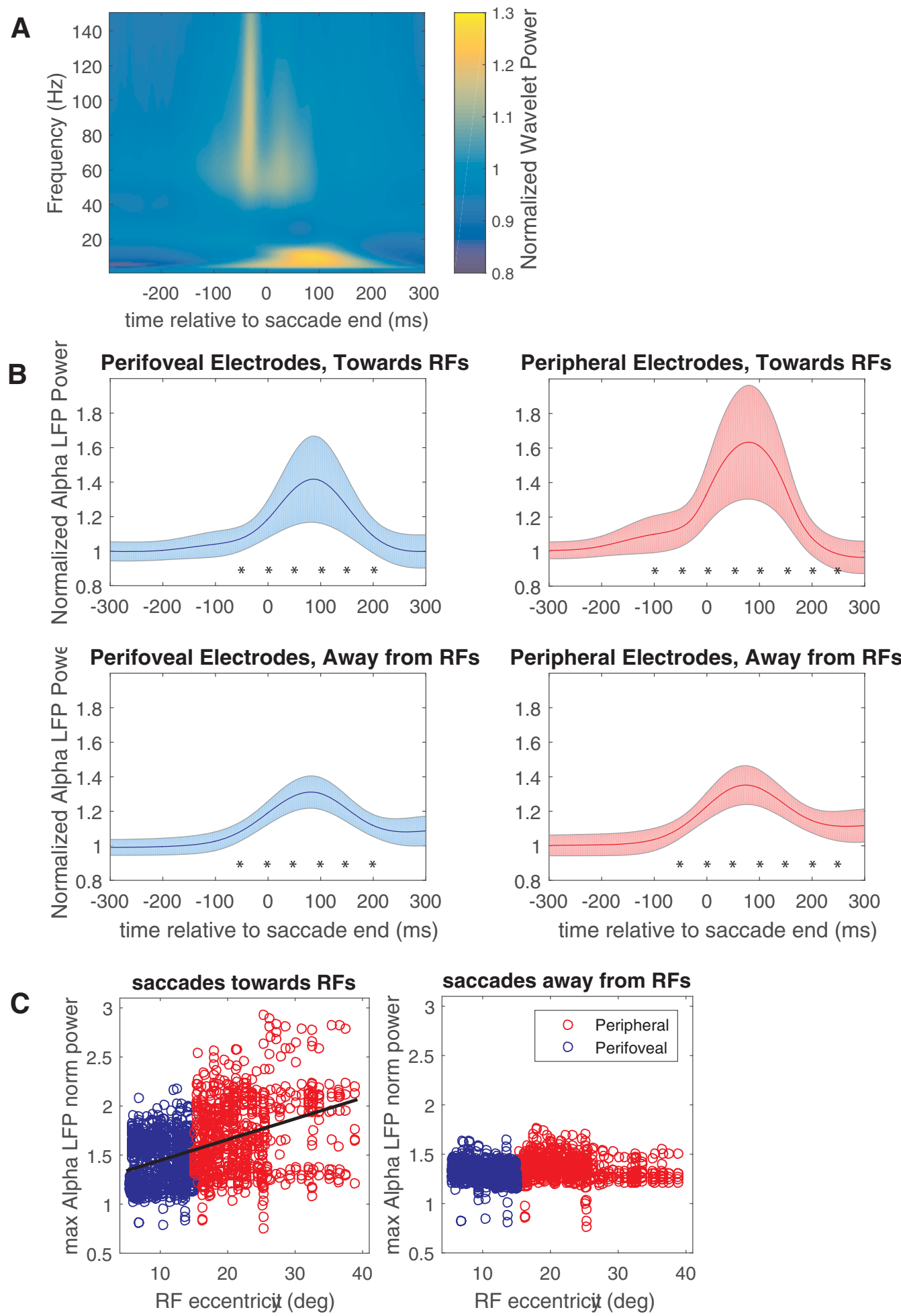

Figure 4. Perisaccadic LFP power modulation. $\boldsymbol{A}$, Saccade-triggered wavelet average across all electrodes and sessions, computed around the end of each saccade. $\boldsymbol{B}, \alpha$ LFP power relative to saccade end, for the perifoveal electrodes (left) and peripheral electrodes (right), during saccades toward the RFs (top) and away from the RFs (bottom). Asterisks indicate $100 \mathrm{~ms}$ bins in which alpha power was significantly different from its pre-saccadic value (two-tailed $t$ test, $p<0.05$ ). C, Peak modulation of $\alpha$ LFP power for both perifoveal (blue) and peripheral (red) electrodes, for toward (left) and away (right) saccades. For toward saccades, the significant correlation ( $r=0.42, p<0.01$ ) between the peak modulation of $\alpha$ LFP power and receptive field eccentricity is depicted by a black line. max, Maximum; norm, normalized.

Finally, to determine whether this association of $\alpha$ power with firing rate modulation was specific to the execution of the saccade, we computed the power of $\alpha$ band LFP signals recorded during steady fixation and related it to the firing rates of V4 neurons at the same time. The results again show an inverse correlation between $\alpha$ LFP power and firing rates during periods of steady fixation (Fig. 7). Consistent with the results around the time of saccades, and previous studies (Nir et al., 2007; Haegens et al., 2011), higher spontaneous $\alpha$ LFP power is accompanied by low firing rates for both perifoveal (Fig. 7, blue trace) and periph- 
A
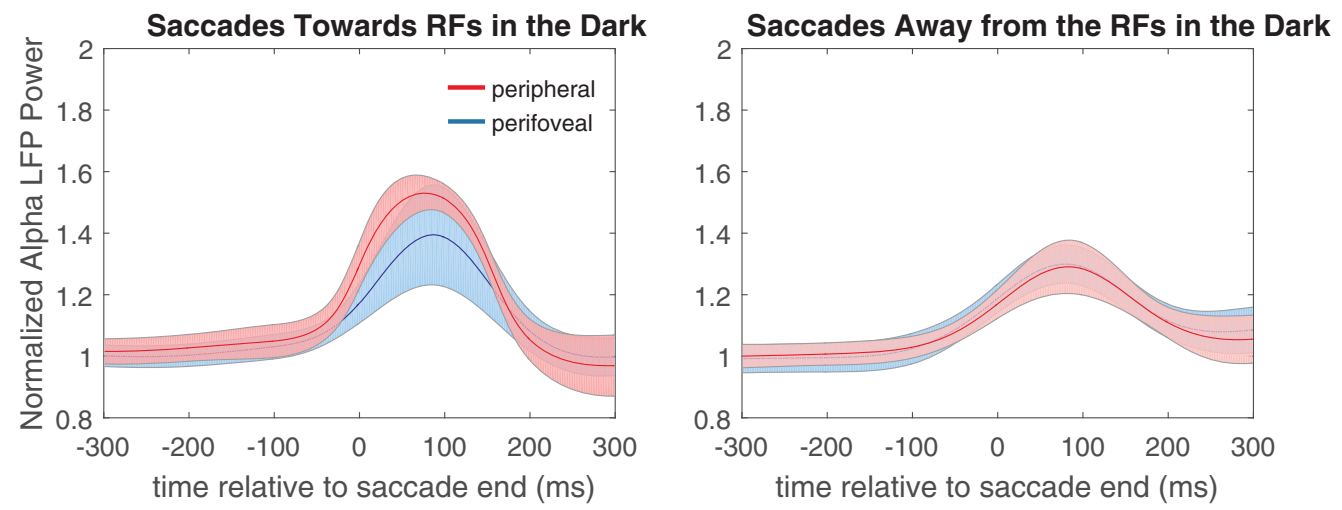

B
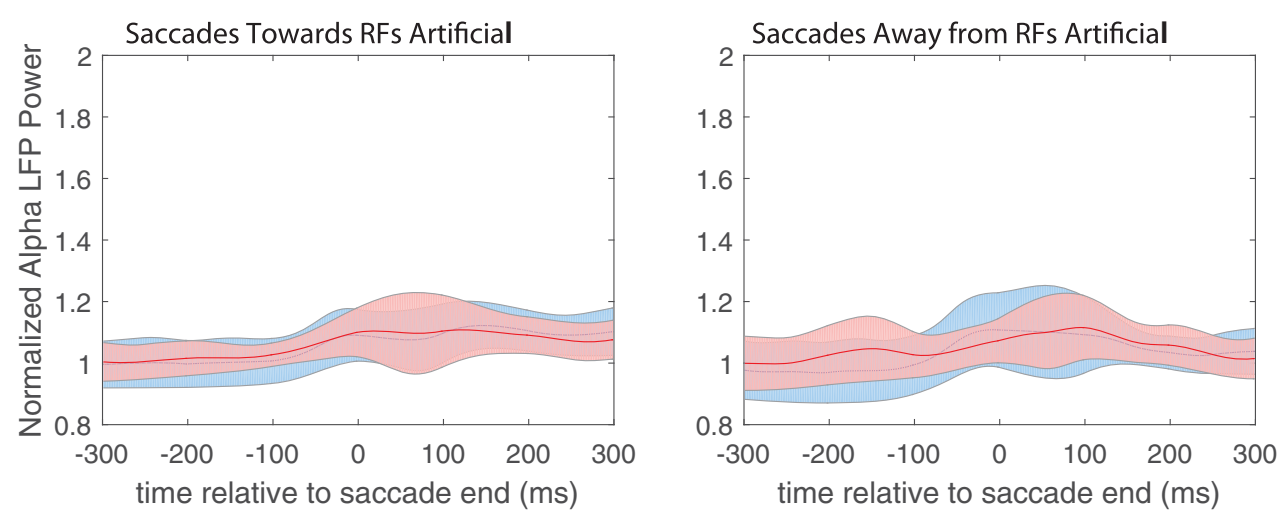

Figure 5. $\quad \alpha$ LFP power modulation during control experiments. A, Average normalized perisaccadic $\alpha$ LFP power for perifoveal (blue trace) and peripheral (red trace) electrodes, for saccades in the dark, for toward (left) and away (right) saccades. B, Average normalized perisaccadic $\alpha$ LFP power for perifoveal (blue trace) and peripheral (red trace) electrodes for artificial toward (left) and away (right) saccades.

eral (Fig. 7, red trace) neurons. Our results therefore suggest that saccadic suppression of the baseline firing of peripheral V4 neurons is primarily driven by increased $\alpha$ LFP power.

\section{Discussion}

We have shown that a significant number of V4 neurons exhibit neural correlates of saccadic suppression (see also Han et al., 2009). This suppression transitions between two phases that are characterized by differences in both their retinotopic organization and their mechanistic aspects. The first phase, occurring before and during the execution of a saccade, is driven by a multiplicative suppression that is roughly the same across all eccentricities. This is followed by a second phase that involves an additive component limited only to peripheral neurons. The transition between these two phases is accompanied by a strong increase in the power of $\alpha$ LFP activity at peripheral V4 sites. Together, these results may account for various psychophysical results and suggest a new mechanistic interpretation of saccadic suppression.

\section{Relationship to psychophysical results}

Additive influences on neuronal populations are, by definition, independent of stimulus characteristics. They can, however, improve or diminish detection performance by pushing weak inputs above or below threshold (Schölvinck et al., 2012). This function has often been hypothesized to be at work in the context of attentional manipulations (Reynolds et al., 1999; Ress et al., 2000). Multiplicative influences, in contrast, scale neural responses in a manner similar to that achieved by increasing stimulus contrast.
Early psychophysical studies of saccadic suppression, using a detection task, reported differential suppression across visual space: suppression was reported to be stronger (Osaka, 1987) and to rebound more quickly (Mitrani et al., 1970) in the central visual field. This could be consistent with the additive mechanism we have reported, which is more pronounced in the central visual field (Fig. 3C, right).

More recently, Knöll et al. (2011) measured suppression relative to contrast thresholds determined at each eccentricity. They found an eccentricity-independent, multiplicative suppression could account for their data and argued that it accounted for the previous results as well. This mechanism is most similar to the multiplicative effect found in our data (Fig. $3 C$, left). Thus, although both types of psychophysical results may be accommodated under a single multiplicative mechanism (Knöll et al., 2011), it would be interesting to determine whether a correlate of the additive suppression we report here can be detected psychophysically.

In addition to the spatial effects described above, our results also bear on the timing of saccadic suppression. Most psychophysical studies (Burr and Morrone, 1996; Ross et al., 1996, 2001; Diamond et al., 2000; Bremmer et al., 2009; Knöll et al., 2011; Dorr and Bex, 2013) have detected suppression for stimuli presented within a broad time window, beginning just before the saccade and ending just after the saccade. Given the range of latencies for V4 responses (Zanos et al., 2015), it appears that the first phase of suppression affects stimuli presented mainly before and during the execution of an eye movement, and the second 
A

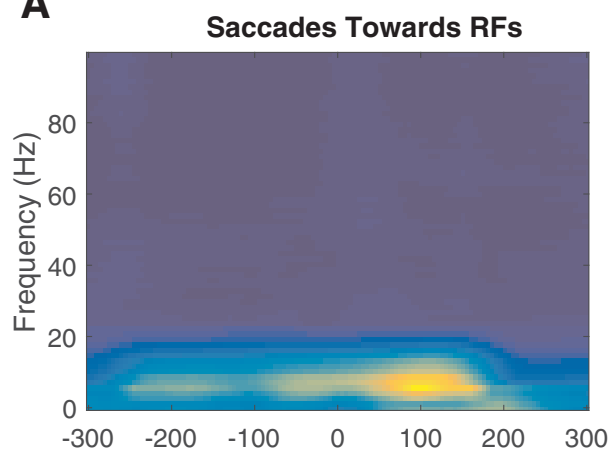

B

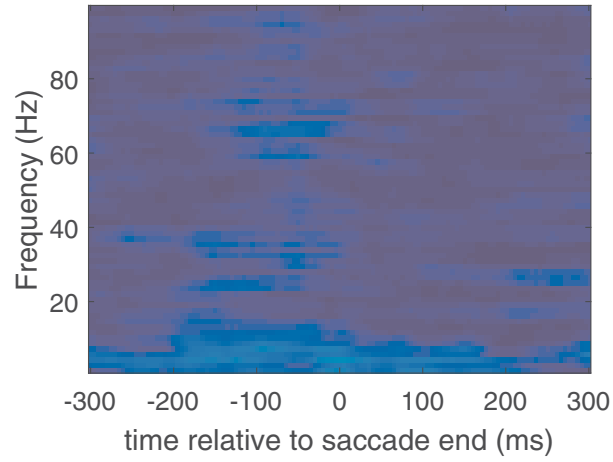

C

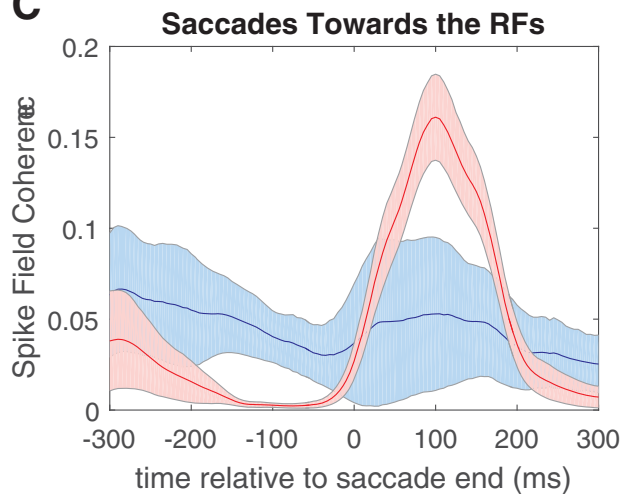

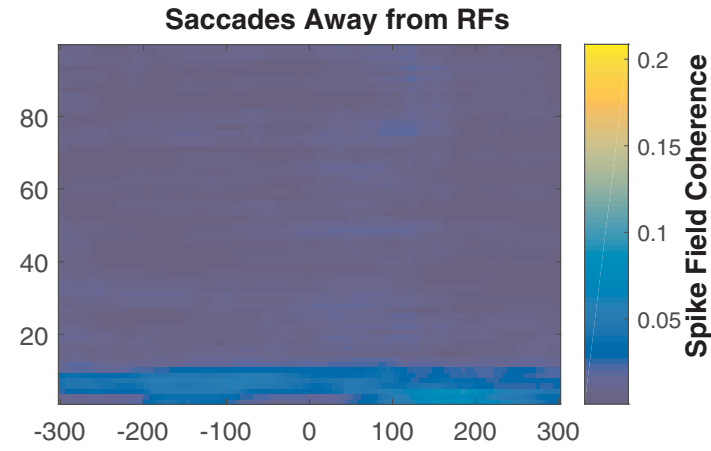
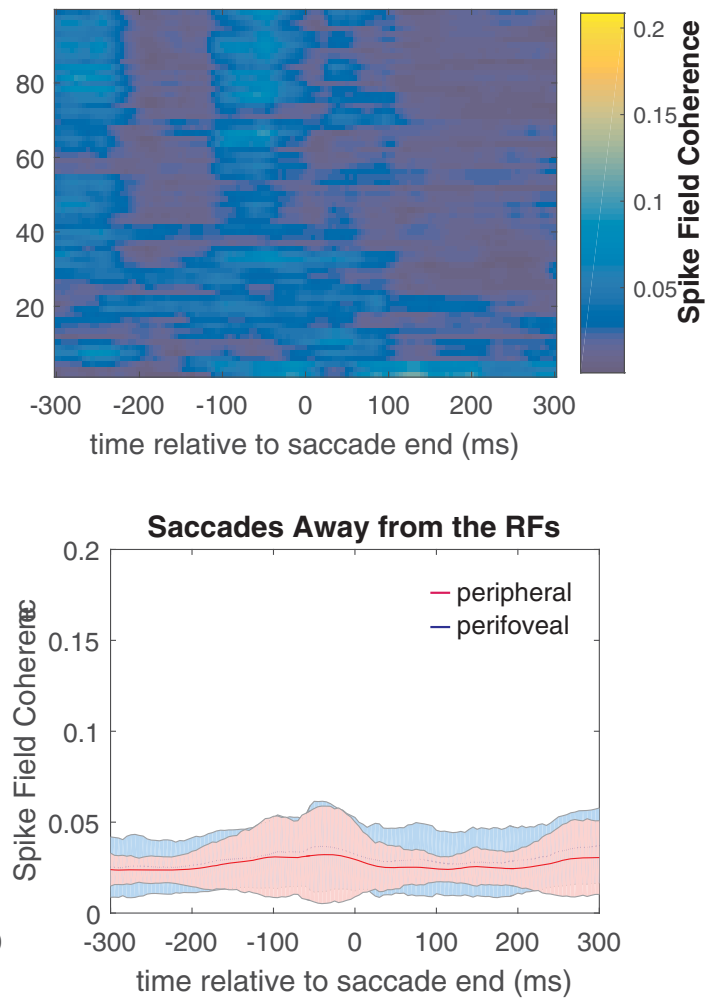

Figure 6. Perisaccadic spike-field coherence. $\boldsymbol{A}$, Example of the SFC calculated for a peripheral neuron with an eccentricity of $27.7^{\circ}$ for toward (left) and away (right) saccades. $\boldsymbol{B}$, Example of the SFC calculated for a perifoveal V4 neuron with an eccentricity of 7.9 $9^{\circ}$. C, Population averages of the $\alpha(7-13 \mathrm{~Hz})$ SFC values around the time of each saccade, for perifoveal (blue) and peripheral (red) neurons and for toward (left) and away (right) saccades.

Table 1. Pairwise noise correlations between all possible pairs of neurons, among and within the perifoveal and peripheral groups, for three time windows relative to saccade end and both saccade directions.

\begin{tabular}{|c|c|c|c|c|c|c|}
\hline & \multicolumn{2}{|l|}{-75 to $0 \mathrm{~ms}$} & \multicolumn{2}{|l|}{$0-75 \mathrm{~ms}$} & \multicolumn{2}{|l|}{$75-150 \mathrm{~ms}$} \\
\hline & Away from RFs & Toward RFs & Away from RFs & Toward RFs & Away from RFs & Toward RFs \\
\hline Perifoveal-Perifoveal & $0.025 \pm 0.0783$ & $0.0208 \pm 0.0756$ & $0.0277 \pm 0.089$ & $0.0222 \pm 0.0789$ & $0.025 \pm 0.0868$ & $0.0232 \pm 0.0710$ \\
\hline Peripheral-Peripheral & $0.0195 \pm 0.0783$ & $0.0212 \pm 0.0779$ & $0.0193 \pm 0.0882$ & $0.0318 \pm 0.0774$ & $0.029 \pm 0.0877$ & $0.0424 \pm 0.0783$ \\
\hline Perifoveal-Peripheral & $0.0266 \pm 0.0776$ & $0.0214 \pm 0.0766$ & $0.0222 \pm 0.0792$ & $0.022 \pm 0.0745$ & $0.0254 \pm 0.0796$ & $0.0216 \pm 0.0676$ \\
\hline
\end{tabular}

Highlighted in bold is the correlation that is significantly higher than all other saccade direction time windows (repeated-measures ANOVA, $p<0.01$ ) and correlations of all other neuronal groups (one-way ANOVA, $p<0.01$ ).

phase affects peripheral stimuli presented right after the completion of the saccade. Whereas the first phase is consistent with the timing of saccadic suppression in most psychophysical and neurophysiology studies, evidence of postsaccadic suppression is rare (Kayama et al., 1979).

Previous work has suggested that saccadic suppression could result from a combination of extraretinal and retinal mechanisms (Burr and Ross, 1982; Burr et al., 1982; Diamond et al., 2000;
Castet et al., 2002). Extraretinal mechanisms involve corollary discharge signals that suppress neural firing, whereas retinal mechanisms involve suppressive signals that depend entirely on the pattern of visual stimulation. A role for extraretinal mechanisms in our results is supported by the fact that suppression starts well before saccade initiation (Fig. 3C, left; Latour, 1962) and that the modulation of $\alpha$ LFPs persists during saccades in the dark (Fig. 5A). Moreover, the pronounced differences in sup- 
Conditional Probability of Spike Occurrence

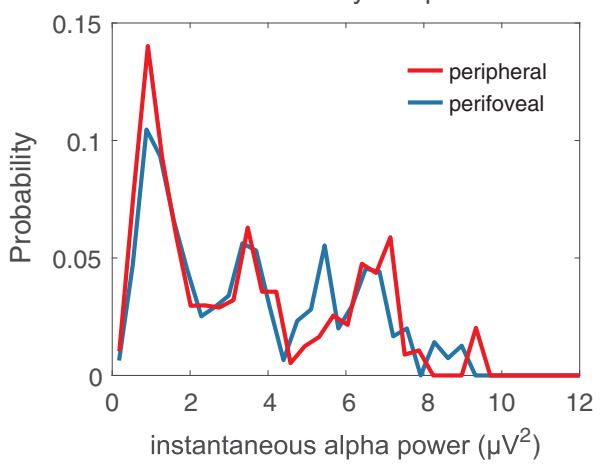

Figure 7. $\alpha$ LFP power correlates with V4 firing rates during fixation. The probability of V4 spike occurrence relative to the power of $\alpha$ band LFPs signals recorded during steady fixation for perifoveal (blue trace) and peripheral (red trace) neurons is shown.

pression for toward and away saccades (Figs. 2C, 4B, C) argue for a role for extraretinal mechanisms, since the pattern of retinal stimulation is very similar in the two cases. Similar results have been found in various other brain areas (Lee and Malpeli, 1998; Reppas et al., 2002; Thiele et al., 2002; Royal et al., 2006; Ibbotson et al., 2008). Collectively, they are consistent with psychophysical experiments (Diamond et al., 2000) in which saccadic suppression remains after retinal influences have been carefully eliminated. They are also consistent with human PET studies showing decreased visual cortex activity during saccadic movements in the dark (Paus et al., 1995; Wenzel et al., 1996; de Jong et al., 2001).

Some psychophysical results (Irwin et al., 1988) have shown a role for a retinal influence in the form of masking caused by the sweep of the visual field across the retina during saccades. We have tried to approximate this condition with artificial saccades, which showed little evidence of suppression in our data (Fig. 5B).

\section{Anatomical basis}

The most common form of saccadic suppression is the reduction of visual motion sensitivity conveyed by the magnocellular pathway, reported both in psychophysical (Burr et al., 1994; Burr and Morrone, 1996; Ross et al., 1996) and electrophysiological studies, in the lateral geniculate nucleus (Fischer et al., 1996; Ramcharan et al., 2001; Reppas et al., 2002) and the dorsal stream of the visual cortex (Thiele et al., 2002; Ibbotson et al., 2008; Bremmer et al., 2009; Crowder et al., 2009). Consistent with the magnocellular hypothesis, suppression does not appear to affect color sensitivity or object discrimination (Ross et al., 1996; Diamond et al., 2000), which are usually considered to rely on the ventral pathway originating with parvocellular neurons in the retina.

Area V4 is considered part of the ventral pathway, so on this basis one might not expect to find saccadic suppression there. However, V4 does receive considerable magnocellular input (Ferrera et al., 1994), and previous studies have reported correlates of saccadic suppression in human fMRI (Kleiser et al., 2004) and in single-neuron activity during saccade preparation (Han et al., 2009). The additive mechanism we have found is most prominent in peripheral neurons, where magnocellular neurons are far more common (Azzopardi et al., 1999).

\section{Functional implications}

Saccades are tightly linked with shifts of attention (Deubel and Schneider, 1996), and so one might expect that much of the underlying neural circuitry is shared. Although attention is usually associated with a multiplicative scaling of neuronal responses in
V4 (McAdams and Maunsell, 1999), there also seems to be a clear connection between attentional modulation and additive effects in our data. Specifically, our results in the visual periphery show a perisaccadic increase in $\alpha$, a decrease in neural firing, and an increase in noise correlations. These effects have all been reported in other contexts (Cohen and Maunsell, 2009; Mitchell et al., 2009; Khayat et al., 2010) to be associated with decreased attention. This suggests that saccadic suppression in the periphery could be viewed as active inattention, perhaps through additive attentional effects inherited from V1 (Thiele et al., 2009).

The overall retinotopic pattern of influences might serve to focus attentional resources on the area around the saccade target in the immediate postsaccadic period. That is, given the nature of our task, attention probably follows the saccade target from its presaccadic peripheral location to its postsaccadic, foveal location (Jonikaitis et al., 2013). In this case, one would expect to find increased processing power in the foveal area of the V4 retinotopic map during the same postsaccadic period in which suppression is found in the periphery.

This hypothetical attentional mechanism, and its association with $\alpha$ LFPs, would be complementary to the influence of $\beta$ oscillations (Zanos et al., 2015), which also seem to enhance firing near the fovea at the expense of the periphery. The influence of $\beta$ oscillations is brought about by a perisaccadic phase reset (Zanos et al., 2015), whereas for $\alpha$ the primary effect is amplitude modulation (Fig. 4). The $\beta$ and $\alpha$ oscillations also exhibit different spatial organizations, the first manifesting as a planar traveling wave (Zanos et al., 2015) and the second as a standing synchronous oscillation. Similar perisaccadic $\alpha$ LFP modulation has been reported in macaque V1 (Ito et al., 2011), accompanied by modulation of neural excitability.

\section{Theoretical implications}

Previous work sought to characterize the nature of presaccadic (Watson and Krekelberg, 2011) and intrasaccadic (Guez et al., 2013) suppression by applying the perceptual template model (PTM; Lu and Dosher, 1998). The results favored a multiplicative, gain-reduction mechanism, and this is consistent with our results for both the presaccadic and intrasaccadic periods (Fig. $3 C$, left). However, the PTM also includes a stage of attentional modulation that is stimulus independent, represented as a noiseinjection step. Our results suggest that this stage might correspond to the postsaccadic, additive phase of saccadic suppression that appears only for peripheral sites of V4 (Fig. 3C, right). Indeed, as evident from our results, this phase manifests as a subtractive baseline reduction, and there is some evidence that correlated noise increases at the same time (Table 1).

The $\alpha$ oscillations have been linked to mechanisms of inhibition, either based on the $\alpha$ oscillation inhibition-timing hypothesis (Klimesch et al., 2007) or the gating-by-inhibition model (Jensen and Mazaheri, 2010). These mechanisms have been supported by studies that reported lower firing rates for neurons that were more strongly correlated with increases in $\alpha$ LFP power (Nir et al., 2007; Haegens et al., 2011). Our results support the inhibitory role of $\alpha$ oscillations, since suppression of peripheral V4 neurons is accompanied by increased LFP power (Fig. 4) and $\alpha$ LFP power correlates negatively with the probability of spiking even during fixation (Fig. 7). Moreover, the suppressed V4 neurons entrain their spikes to $\alpha$ oscillations (Fig. 6), supporting the inhibition-timing hypothesis. An expansion of the gating-byinhibition model relates $\alpha$ oscillations with attention and prioritization of salient stimuli (Jensen et al., 2012). This model indicates that $\alpha$ activity modulates perception by producing 
periodic pulses of inhibition, outlining a potential theoretical framework for our neurophysiological results.

\section{References}

Ahrens MB, Linden JF, Sahani M (2008) Nonlinearities and contextual influences in auditory cortical responses modeled with multilinear spectrotemporal methods. J Neurosci 28:1929-1942. CrossRef Medline

Azzopardi P, Jones KE, Cowey A (1999) Uneven mapping of magnocellular and parvocellular projections from the lateral geniculate nucleus to the striate cortex in the macaque monkey. Vision Res 39:2179-2189. CrossRef Medline

Binda P, Cicchini GM, Burr DC, Morrone MC (2009) Spatiotemporal distortions of visual perception at the time of saccades. J Neurosci 29: 13147-13157. CrossRef Medline

Bremmer F, Kubischik M, Hoffmann KP, Krekelberg B (2009) Neural dynamics of saccadic suppression. J Neurosci 29:12374-12383. CrossRef Medline

Burr DC, Morrone MC (1996) Temporal impulse response functions for luminance and colour during saccades. Vision Res 36:2069-2078. CrossRef Medline

Burr DC, Ross J (1982) Contrast sensitivity at high velocities. Vision Res 22:479-484. CrossRef Medline

Burr DC, Holt J, Johnstone JR, Ross J (1982) Selective depression of motion sensitivity during saccades. J Physiol 333:1-15. CrossRef Medline

Burr DC, Morrone MC, Ross J (1994) Selective suppression of the magnocellular visual pathway during saccadic eye movements. Nature 371: 511-513. CrossRef Medline

Burr DC, Morgan MJ, Morrone MC (1999) Saccadic suppression precedes visual motion analysis. Curr Biol 9:1207-1209. CrossRef Medline

Castet E, Jeanjean S, Masson GS (2002) Motion perception of saccadeinduced retinal translation. Proc Natl Acad Sci U S A 99:15159-15163. CrossRef Medline

Churan J, Guitton D, Pack CC (2011) Context dependence of receptive field remapping in superior colliculus. J Neurophysiol 106:1862-1874. CrossRef Medline

Churan J, Guitton D, Pack CC (2012) Perisaccadic remapping and rescaling of visual responses in macaque superior colliculus. PLoS ONE 7:e52195.

Cohen MR, Maunsell JH (2009) Attention improves performance primarily by reducing interneuronal correlations. Nat Neurosci 12:1594-1600. CrossRef Medline

Connor CE, Gallant JL, Preddie DC, Van Essen DC (1996) Responses in area V4 depend on the spatial relationship between stimulus and attention. J Neurophysiol 75:1306-1308. Medline

Crowder NA, Price NS, Mustari MJ, Ibbotson MR (2009) Direction and contrast tuning of macaque MSTd neurons during saccades. J Neurophysiol 101:3100-3107. CrossRef Medline

de Jong BM, van Weerden TW, Haaxma R (2001) Opsoclonus-induced occipital deactivation with a region-specific distribution. Vision Res 41: 1209-1214. CrossRef Medline

Desimone R, Schein SJ (1987) Visual properties of neurons in area V4 of the macaque: sensitivity to stimulus form. J Neurophysiol 57:835-868. Medline

Deubel H, Schneider WX (1996) Saccade target selection and object recognition: evidence for a common attentional mechanism. Vision Res 36: 1827-1837. CrossRef Medline

Diamond MR, Ross J, Morrone MC (2000) Extraretinal control of saccadic suppression. J Neurosci 20:3449-3455. Medline

Dorr M, Bex PJ (2013) Peri-saccadic natural vision. J Neurosci 33: 1211-1217. CrossRef Medline

Ferrera VP, Nealey TA, Maunsell JH (1994) Responses in macaque visual area V4 following inactivation of the parvocellular and magnocellular LGN pathways. J Neurosci 14:2080-2088. Medline

Fischer B, Boch R (1981) Enhanced activation of neurons in prelunate cortex before visually guided saccades of trained rhesus monkeys. Exp Brain Res 44:129-137. Medline

Fischer WH, Schmidt M, Stuphorn V, Hoffmann KP (1996) Response properties of relay cells in the A-laminae of the cat's dorsal lateral geniculate nucleus after saccades. Exp Brain Res 110:435-445. Medline

Fiser J, Chiu C, Weliky M (2004) Small modulation of ongoing cortical dynamics by sensory input during natural vision. Nature 431:573-578. CrossRef Medline

Fries P, Neuenschwander S, Engel AK, Goebel R, Singer W (2001) Rapid feature selective neuronal synchronization through correlated latency shifting. Nat Neurosci 4:194-200. CrossRef Medline
Gattass R, Sousa AP, Gross CG (1988) Visuotopic organization and extent of V3 and V4 of the macaque. J Neurosci 8:1831-1845. Medline

Ghose GM, Ts'o DY (1997) Form processing modules in primate area V4. J Neurophysiol 77:2191-2196. Medline

Goupillaud P, Grossmann A, Morlet J (1984) Cycle-octave and related transforms in seismic signal analysis. Geoexploration 23:85-102. CrossRef

Gu XJ, Hu M, Li B, Hu XT (2014) The role of contrast adaptation in saccadic suppression in humans. PLoS One 9:e86542. CrossRef Medline

Guez J, Morris AP, Krekelberg B (2013) Intrasaccadic suppression is dominated by reduced detector gain. J Vis 13:4. CrossRef Medline

Haegens S, Nácher V, Luna R, Romo R, Jensen O (2011) $\alpha$-Oscillations in the monkey sensorimotor network influence discrimination performance by rhythmical inhibition of neuronal spiking. Proc Natl Acad Sci U S A 108:19377-19382. CrossRef Medline

Han X, Xian SX, Moore T (2009) Dynamic sensitivity of area V4 neurons during saccade preparation. Proc Natl Acad Sci U S A 106:13046-13051. CrossRef Medline

Ibbotson MR, Crowder NA, Cloherty SL, Price NS, Mustari MJ (2008) Saccadic modulation of neural responses: possible roles in saccadic suppression, enhancement, and time compression. J Neurosci 28:10952-10960. CrossRef Medline

Irwin DE, Brown JS, Sun JS (1988) Visual masking and visual integration across saccadic eye movements. J Exp Psychol Gen 117:276-287. CrossRef Medline

Ito J, Maldonado P, Singer W, Grün S (2011) Saccade-related modulations of neuronal excitability support synchrony of visually elicited spikes. Cereb Cortex 21:2482-2497. CrossRef Medline

Jensen O, Mazaheri A (2010) Shaping functional architecture by oscillatory alpha activity: gating by inhibition. Front Hum Neurosci 4:186. CrossRef Medline

Jensen O, Bonnefond M, VanRullen R (2012) An oscillatory mechanism for prioritizing salient unattended stimuli. Trends Cogn Sci 16:200-206. CrossRef Medline

Joiner WM, Cavanaugh J, Wurtz RH (2011) Modulation of shifting receptive field activity in frontal eye field by visual salience. J Neurophysiol 106:1179-1190. CrossRef Medline

Jonikaitis D, Szinte M, Rolfs M, Cavanagh P (2013) Allocation of attention across saccades. J Neurophysiol 109:1425-1434. CrossRef Medline

Kayama Y, Riso RR, Bartlett JR, Doty RW (1979) Luxotonic responses of units in macaque striate cortex. J Neurophysiol 42:1495-1517. Medline

Khayat PS, Niebergall R, Martinez-Trujillo JC (2010) Frequency-dependent attentional modulation of local field potential signals in macaque area MT. J Neurosci 30:7037-7048. CrossRef Medline

Kleiser R, Seitz RJ, Krekelberg B (2004) Neural correlates of saccadic suppression in humans. Curr Biol 14:386-390. CrossRef Medline

Klimesch W, Sauseng P, Hanslmayr S (2007) EEG alpha oscillations: the inhibition-timing hypothesis. Brain Res Rev 53:63-88. CrossRef Medline

Knöll J, Binda P, Morrone MC, Bremmer F (2011) Spatiotemporal profile of peri-saccadic contrast sensitivity. J Vis 11:15. CrossRef Medline

Krekelberg B, Kubischik M, Hoffmann KP, Bremmer F (2003) Neural correlates of visual localization and perisaccadic mislocalization. Neuron 37:537-545. CrossRef Medline

Lakatos P, Shah AS, Knuth KH, Ulbert I, Karmos G, Schroeder CE (2005) An oscillatory hierarchy controlling neuronal excitability and stimulus processing in the auditory cortex. J Neurophysiol 94:1904-1911. CrossRef Medline

Lakatos P, O'Connell MN, Barczak A, Mills A, Javitt DC, Schroeder CE (2009) The leading sense: supramodal control of neurophysiological context by attention. Neuron 64:419-430. CrossRef Medline

Latour PL (1962) Visual threshold during eye movements. Vision Res 2:261-262. CrossRef Medline

Lee D, Malpeli JG (1998) Effects of saccades on the activity of neurons in the cat lateral geniculate nucleus. J Neurophysiol 79:922-936. Medline

Lu ZL, Dosher BA (1998) External noise distinguishes attention mechanisms. Vision Res 38:1183-1198. CrossRef Medline

Matin E, Clymer AB, Matin L (1972) Metacontrast and saccadic suppression. Science 178:179-182. CrossRef Medline

McAdams CJ, Maunsell JH (1999) Effects of attention on orientationtuning functions of single neurons in macaque cortical area V4. J Neurosci 19:431-441. Medline

McFarland JM, Bondy AG, Saunders RC, Cumming BG, Butts DA (2015) Saccadic modulation of stimulus processing in primary visual cortex. Nat Commun 6:8110. CrossRef Medline 
Mineault PJ, Zanos TP, Pack CC (2013) Local field potentials reflect multiple spatial scales in V4. Front Comput Neurosci 7:21. CrossRef Medline

Mitchell JF, Sundberg KA, Reynolds JH (2009) Spatial attention decorrelates intrinsic activity fluctuations in macaque area V4. Neuron 63: 879-888. CrossRef Medline

Mitrani L, Mateeff S, Yakimoff N (1970) Temporal and spatial characteristics of visual suppression during voluntary saccadic eye movement. Vision Res 10:417-422. CrossRef Medline

Moore T (1999) Shape representations and visual guidance of saccadic eye movements. Science 285:1914-1917. CrossRef Medline

Moore T, Tolias AS, Schiller PH (1998) Visual representations during saccadic eye movements. Proc Natl Acad Sci U S A 95:8981-8984. CrossRef Medline

Neupane S, Guitton D, Pack CC (2016a) Two distinct types of remapping in primate cortical area V4. Nat Commun 7:10402. CrossRef Medline

Neupane S, Guitton D, Pack CC (2016b) Dissociation of forward and convergent remapping in primate visual cortex. Curr Biol 26:R491-R492. CrossRef Medline

Nir Y, Fisch L, Mukamel R, Gelbard-Sagiv H, Arieli A, Fried I, Malach R (2007) Coupling between neuronal firing rate, gamma LFP, and BOLD fMRI is related to interneuronal correlations. Curr Biol 17:1275-1285. CrossRef Medline

Osaka N (1987) Variation of saccadic suppression with target eccentricity. Ophthalmic Physiol Opt 7:499-501. CrossRef Medline

Park M, Pillow JW. Bayesian active learning with localized priors for fast receptive field characterization. In: NIPS; 2012:2357-2365.

Paus T, Marrett S, Worsley KJ, Evans AC (1995) Extraretinal modulation of cerebral blood flow in the human visual cortex: implications for saccadic suppression. J Neurophysiol 74:2179-2183. Medline

Quiroga RQ, Nadasdy Z, Ben-Shaul Y (2004) Unsupervised spike detection and sorting with wavelets and superparamagnetic clustering. Neural Comput 16:1661-1687. CrossRef Medline

Rajkai C, Lakatos P, Chen CM, Pincze Z, Karmos G, Schroeder CE (2008) Transient cortical excitation at the onset of visual fixation. Cereb Cortex 18:200-209. CrossRef Medline

Ramcharan EJ, Gnadt JW, Sherman SM (2001) The effects of saccadic eye movements on the activity of geniculate relay neurons in the monkey. Vis Neurosci 18:253-258. CrossRef Medline

Reppas JB, Usrey WM, Reid RC (2002) Saccadic eye movements modulate visual responses in the lateral geniculate nucleus. Neuron 35:961-974. CrossRef Medline

Ress D, Backus BT, Heeger DJ (2000) Activity in primary visual cortex predicts performance in a visual detection task. Nat Neurosci 3:940-945.
Reynolds JH, Chelazzi L, Desimone R (1999) competitive mechanisms subserve attention in macaque areas V2 and V4. J Neurosci 19:1736-1753.

Ross J, Burr D, Morrone C (1996) Suppression of the magnocellular pathway during saccades. Behav Brain Res 80:1-8. CrossRef Medline

Ross J, Morrone MC, Goldberg ME, Burr DC (2001) Changes in visual perception at the time of saccades. Trends Neurosci 24:113-121. CrossRef Medline

Royal DW, Sáry G, Schall JD, Casagrande VA (2006) Correlates of motor planning and postsaccadic fixation in the macaque monkey lateral geniculate nucleus. Exp Brain Res 168:62-75. CrossRef Medline

Schölvinck ML, Friston KJ, Rees G (2012) The influence of spontaneous activity on stimulus processing in primary visual cortex. Neuroimage 59:2700-2708. CrossRef Medline

Steriade M, McCormick DA, Sejnowski TJ (1993) Thalamocortical oscillations in the sleeping and aroused brain. Science 262:679-685. CrossRef Medline

Thiele A, Henning P, Kubischik M, Hoffmann KP (2002) Neural mechanisms of saccadic suppression. Science 295:2460-2462. CrossRef Medline

Thiele A, Pooresmaeili A, Delicato LS, Herrero JL, Roelfsema PR (2009) Additive effects of attention and stimulus contrast in primary visual cortex. Cereb Cortex 19:2970-2981. CrossRef Medline

Tolias AS, Moore T, Smirnakis SM, Tehovnik EJ, Siapas AG, Schiller PH (2001) Eye movements modulate visual receptive fields of V4 neurons. Neuron 29:757-767. CrossRef Medline

Watson T, Krekelberg B (2011) An equivalent noise investigation of saccadic suppression. J Neurosci 31:6535-6541. CrossRef Medline

Wenzel R, Bartenstein P, Dieterich M, Danek A, Weindl A, Minoshima S, Ziegler S, Schwaiger M, Brandt T (1996) Deactivation of human visual cortex during involuntary ocular oscillations. Brain 119:101-110. CrossRef Medline

Wood S (2006) Generalized additive models. Boca Raton, FL: Chapman and Hall/CRC.

Wurtz RH (2008) Neuronal mechanisms of visual stability. Vision Res 48: 2070-2089. CrossRef Medline

Zanos TP, Mineault PJ, Monteon JA, Pack CC (2011a) Functional connectivity during surround suppression in macaque area V4. Paper presented at Annual International Conference of the IEEE Engineering in Medicine and Biology Society, Boston, MA, September 2011.

Zanos TP, Mineault PJ, Pack CC (2011b) Removal of spurious correlations between spikes and local field potentials. J Neurophysiol 105:474-486. CrossRef Medline

Zanos TP, Mineault PJ, Nasiotis KT, Guitton D, Pack CC (2015) A sensorimotor role for traveling waves in primate visual cortex. Neuron 85 : 615-627. CrossRef Medline 